\title{
Nephrogenic diabetes insipidus
}

INSERM

\section{Source}

INSERM. (1999). Orphanet: an online rare disease and orphan drug data base.

Nephrogenic diabetes insipidus. ORPHA:223

Nephrogenic diabetes insipidus (NDI) is characterized by polyuria with polydipsia,

recurrent bouts of fever, constipation, and acute hypernatremic dehydration after birth that may cause neurological sequelae. Polyuria may exceed 10 litres in children. 